\title{
Age, Sex, Population Density and COVID-19 Pandemic in Thailand: A Nationwide Descriptive Correlational Study
}

\author{
Suebsarn Ruksakulpiwat, MMed. ${ }^{1}$, Wendie Zhou, B.S. ${ }^{2,3}$, Chantira Chiaranai, Ph.D. ${ }^{4}$, \\ Phongthon Saengchut, M.Eng. ${ }^{5}$, Jane E. Vonck, MSN, FNP-C ${ }^{6}$
}

'Department of Medical Nursing, Faculty of Nursing, Mahidol University, Bangkoknoi, Bangkok 10700, Thailand.

${ }^{2}$ The Second Affiliated Hospital of Harbin Medical University, Harbin 150001 China.

${ }^{3}$ School of Nursing, Harbin Medical University, Harbin 150001 China.

${ }^{4}$ Institute of Nursing, Suranaree University of Technology, Mueang, Nakhonratchasima 30000, Thailand.

${ }^{5}$ Program of Public Health, Western University, Huai Krachao, Kanchanaburi 71170, Thailand.

${ }^{6}$ The University of Wisconsin-Madison, Madison, WI 53715, United States.

Received 8 April 2021 • Revised 30 May 2021 • Accepted 30 June 2021 • Published online 3 September 2021

\begin{abstract}
:
Objective: It is reported that age and sex have been identified as potential risk factors for severe outcomes and the distribution of coronavirus disease (COVID-19), although the specifics of these relationships are unclear. Furthermore, little is known about the relationship between age, sex, COVID-19, and population density in Thailand. This study proposed to examine the relationships among age, sex, population density, and the number of COVID-19 patients in Thailand.

Material and Methods: In this nationwide descriptive correlational study, the dataset of daily COVID-19 cases in Thailand between January 12, 2020, and November 30, 2020, and population density (people $/ \mathrm{km}^{2}$ ) in each province of Thailand was retrieved from the Open Government Data of Thailand, the Registration Office Department of the Interior, the Ministry of the Interior, and the National Statistical Office of Thailand. Chi-square and Pearson product-moment correlation were used to determine the difference and relationships among studied variables. Simple linear regression was used to predict the number of COVID-19 cases based on population density.
\end{abstract}

Results: The findings illustrated a significant difference between male and female patients, in which the number of male patients was higher than female patients across age groups 31-45 years, 40-60 years, and >60 years $(p-v a l u e<0.010)$. Further, population density was significantly associated with the number of COVID-19 cases.

Contact: Suebsarn Ruksakulpiwat, MMed.

Department of Medical Nursing, Faculty of Nursing, Mahidol University,

Bangkoknoi, Bangkok 10700, Thailand.

E-mail: suebsarn25@gmail.com

This is an open access article under the CC BY-NC-ND license

(http://www.jhsmr.org/index.php/jhsmr/about/editorialPolicies\#openAccessPolicy). 
Conclusion: This investigation would provide intervention planning implications during potential future pandemics, especially in groups at higher risk (males, age 17-46 years old, and people living in high-density population areas).

Keywords: age, COVID-19, population density, public health, sex

\section{Introduction}

In December 2019, the first pneumonia case of undiscovered origin was identified in Wuhan, Hubei province, China, and was later confirmed as coronavirus disease COVID-19, which was generated by Severe Acute Respiratory Syndrome Coronavirus 2 (SARS-CoV-2). ${ }^{1}$ Thereafter, the World Health Organization officially declared COVID-19 a public health emergency of international concern. In February 2020, there were roughly 81,000 COVID-19 cases worldwide. ${ }^{2}$ Currently, as of March 17, 2020, COVID-19 has taken around 2.6 million lives worldwide, with about 97 million accumulated documented cases. ${ }^{3}$ Thailand, a country located in Southeast Asia, announced the first COVID-19 case on January 13, 2020. ${ }^{4}$ Most recently, as of March 17, 2020, nationally there have been 27,402 confirmed COVID-19 cases, 88 deaths, and 26,339 recovered, with total testing of 23,234 per 1 million population. $^{3}$

It is reported that certain ages and sex have been identified as potential risk factors for severe outcomes and the distribution of COVID-19. ${ }^{5}$ The Morbidity and Mortality Weekly Report revealed that among the United States of America (USA) population, younger adults (20-29 years) were more likely to contribute to community transmission of COVID-19, as they accounted for more than $20.0 \%$ of all confirmed cases. ${ }^{5}$ Furthermore, fatality was highest in persons aged equal to or more than 85 (10.0\% to $27.0 \%)$, and no fatalities were reported among persons aged equal to or less than 19 years. ${ }^{6}$ Regarding sex, although numerous reports have shown the difference between male and female COVID-19 cases, there has been inconsistency. For example, reports from China and several European countries stated that there were roughly similar numbers of COVID-19 cases between men and women. ${ }^{7}$ However, a study aimed to determine the distribution of COVID-19 by sex amongst the Danish population showed that male COVID-19 infections had more than $50.0 \%$ higher risk than women of all-cause death, severe COVID-19 infection, or Intensive Care Unit (ICU) admission. ${ }^{8}$ Likewise, Klein and colleagues $(2020)^{7}$ reported a higher number of men than women regarding COVID-19 cases, hospitalization, and deaths per 100,000 people in New York city. Since little is known about the relationship between age, sex, and the number of COVID-19 cases in Thailand, this study aimed to examine the correlation amongst these variables.

Age and sex were not the only potential factors identified in the spread of COVID-19; environmental factors such as temperature, humidity, or air pollution were also noted as potential risk factors. ${ }^{9}$ Moreover, a previous study in Japan illustrated that population density was a significant factor affecting the spread of COVID-19 (p-value<0.050). ${ }^{9}$ However, the difference in environment between Japan and Thailand would provide a different perspective.

In this nationwide descriptive correlational study, the difference between age and sex in the number of COVID-19 cases was determined. Moreover, the correlation between population density and the spread of COVID-19 in Thailand was also examined. To date, this is the first study to present the effect of age, sex, and environmental factors on COVID-19 in Thailand. The findings of this study contribute important knowledge to environmental and medical disciplines which could be used for intervention planning during potential future pandemics, including the second or third wave of the COVID-19 pandemic. 


\section{Material and Methods}

The dataset on daily COVID-19 cases in Thailand was collected between January 12, 2020, and November 30, 2020 (based on the date of announcement). This data was composed of 3,998 confirmed COVID-19 patients' age, sex, nationality, notification date, announcement date, and the province of onset. Data were retrieved from the Open Government Data of Thailand, Data ID: 8a956917-436d4afd-a2d4-59e4dd8e906e, Contact person: oudycovid@ gmail.com, License: DGA Open Government License. The data regarding population density (people $\mathrm{km}^{2}$ ) in each province in Thailand was retrieved from The Registration Office Department of the Interior, the Ministry of the Interior of Thailand, and The National Statistical Office of Thailand. Since the authors identified and reviewed data from open government data resources with permission and did not involve human participants, the study was exempt from Institutional Review Board approval.

Firstly, chi-square test was used to determine the difference between age groups (year) $(0-16,17-30,31-45$, 46-60, and >60) and sex (male and female). Furthermore, frequency, percentage, chi-square tests with a significant value (Pearson chi-square, Likelihood Ratio, Linear-byLinear Association) were reported to answer the research question of the likelihood of the distribution of males and females in each age group. The frequency and percentage of COVID-19 cases ranked by nationality were also reported using the Pie chart to show the proportion of COVID-19 cases by different nationalities. The number of COVID-19 cases by area (based on the province of onset) was reported using the COVID-19 case density map, divided into six categories by the number of COVID-19 cases (0, 1-100, >100-200, >200-300, >300-400, and >400). Furthermore, Thailand's population density by province was reported using a population density map, divided into five categories (people $\mathrm{km}^{2}$ ) (0-49.9, > 49.9-74.9, >74.9-99.9, $>99.9-124.9$, and >124.9). Finally, since the population density (people $/ \mathrm{km}^{2}$ ) and the number of COVID-19 cases were continuous level variables, Pearson's product-moment correlation coefficient was used to examine the relationships between the population density and the COVID-19 cases. Moreover, simple linear regression was conducted to predict the number of COVID-19 cases based on population density (people $\mathrm{km}^{2}$ ). Statistical analyses were performed using Statistical Package for the Social Sciences (SPSS) Statistics V. 20.0.

\section{Results}

Table 1 shows difference in age groups of patients with COVID-19 by sex and Table 2 displays chi-square tests of age groups of patients with COVID-19 by sex (Pearson Chi Square=92.259, (degrees of freedom) $d f=$ 4, p-value $<0.001$, Likelihood Ratio=93.361, $d f=4, p$-value $<0.010$, Linear-by-Linear Association=86.222, $\mathrm{df}=1$, p-value<0.010). In this analysis, 3,998 COVID-19 patients were composed of 2,235 males (55.9\%) and 1,763 females $(44.1 \%)$. In $0-16$ years age group (male $(n=77,1.9 \%)$ VS female $(n=81,2.0 \%)$ and $17-30$ years (male $(n=615,15.4 \%)$ VS female $(n=674,16.9 \%))$ showed a slight difference between male and female patients. However, in age groups 31-45 years (male $(n=739,18.5 \%)$ VS female $(n=598$, $15.0 \%)$ ), 46-60 years (male $(n=547,13.7 \%)$ VS female $(n=293,7.3 \%))$, and $>60$ years (male $(n=257,6.4 \%)$ VS female $(n=188,3.0 \%))$ a significant difference was shown between male and female patients, where the number of male patients was clearly higher than female patients across these age groups ( $p$-value<0.010). Moreover, age groups 17-30 years and 31-46 years accounted for almost $66.0 \%$ of all COVID-19 cases (Table 1). 
Table 1 Age groups of patients with COVID-19 by sex

\begin{tabular}{|c|c|c|c|c|}
\hline \multirow{2}{*}{\multicolumn{2}{|c|}{ Age groups of patients with COVID-19 }} & \multicolumn{2}{|c|}{ Sex } & \multirow{2}{*}{ Total } \\
\hline & & Male & Female & \\
\hline \multicolumn{5}{|l|}{ Age group } \\
\hline \multirow[t]{4}{*}{$0-16$ years } & Count & 77 & 81 & 158 \\
\hline & Expected count & 88.3 & 69.7 & 158.0 \\
\hline & $\%$ within sex & $3.4 \%$ & $4.6 \%$ & $4.0 \%$ \\
\hline & $\%$ of total & $1.9 \%$ & $2.0 \%$ & $4.0 \%$ \\
\hline \multirow[t]{4}{*}{$17-30$ years } & Count & 615 & 674 & 1,289 \\
\hline & Expected count & 720.6 & 568.4 & $1,289.0$ \\
\hline & $\%$ within sex & $27.5 \%$ & $38.2 \%$ & $32.2 \%$ \\
\hline & $\%$ of total & $15.4 \%$ & $16.9 \%$ & $32.2 \%$ \\
\hline \multirow[t]{4}{*}{$31-45$ years } & Count & 739 & 598 & 1,337 \\
\hline & Expected count & 747.4 & 589.6 & 1337.0 \\
\hline & $\%$ within sex & $33.1 \%$ & $33.9 \%$ & $33.4 \%$ \\
\hline & $\%$ of total & $18.5 \%$ & $15.0 \%$ & $33.4 \%$ \\
\hline \multirow[t]{4}{*}{$46-60$ years } & Count & 547 & 292 & 839 \\
\hline & Expected count & 469.0 & 370.0 & 839.0 \\
\hline & $\%$ within sex & $24.5 \%$ & $16.6 \%$ & $21.0 \%$ \\
\hline & $\%$ of total & $13.7 \%$ & $7.3 \%$ & $21.0 \%$ \\
\hline \multirow[t]{4}{*}{$>60$ years } & Count & 257 & 118 & 375 \\
\hline & Expected count & 209.6 & 165.4 & 375.0 \\
\hline & $\%$ within sex & $11.5 \%$ & $6.7 \%$ & $9.4 \%$ \\
\hline & $\%$ of total & $6.4 \%$ & $3.0 \%$ & $9.4 \%$ \\
\hline \multirow{4}{*}{ Total } & Count & 2,235 & 1,763 & 3,998 \\
\hline & Expected count & $2,235.0$ & $1,763.0$ & $3,998.0$ \\
\hline & $\%$ within sex & $100.0 \%$ & $100.0 \%$ & $100.0 \%$ \\
\hline & $\%$ of total & $55.9 \%$ & $44.1 \%$ & $100.0 \%$ \\
\hline
\end{tabular}

Table 2 Chi-square tests of age groups of patients with COVID-19 by sex

\begin{tabular}{llll}
\hline & Value & df & p-value \\
\hline Pearson chi-square & 92.259 & 4 & $<0.001$ \\
Likelihood ratio & 93.361 & 4 & $<0.001$ \\
Linear-by-linear association & 86.222 & 1 & $<0.001$ \\
N of valid cases & 3,998 & & \\
\hline
\end{tabular}

$\mathrm{df}=$ degree of freedom, $\mathrm{N}=$ number of COVID-19 cases
Overall, when classifying the data by nationality, the total of 3,998 COVID-19 patient cases consisted of 65 nationalities. Figure 1 shows the top 10 COVID-19 cases in Thailand ranked by nationality. Most COVID-19 patients were from Thailand $(n=3,425,85.6 \%)$ followed by Myanmar $(n=72,1.8 \%)$, India $(n=64,1.6 \%)$, France $(n=43,1.1 \%)$, China ( $n=36,0.9 \%)$, United Kingdom $(n=36,0.9 \%)$, USA $(n=34,0.9 \%)$, Russia $(n=23,0.6 \%)$, Japan $(n=17,0.4 \%)$, and Unspecified (no nationality reported) ( $n=21,0.5 \%$ ), respectively. Other nationalities accounted for $<0.5 \%$ each (all information from Open Government Data of Thailand) (https://data.go.th/dataset/covid-19-daily). 


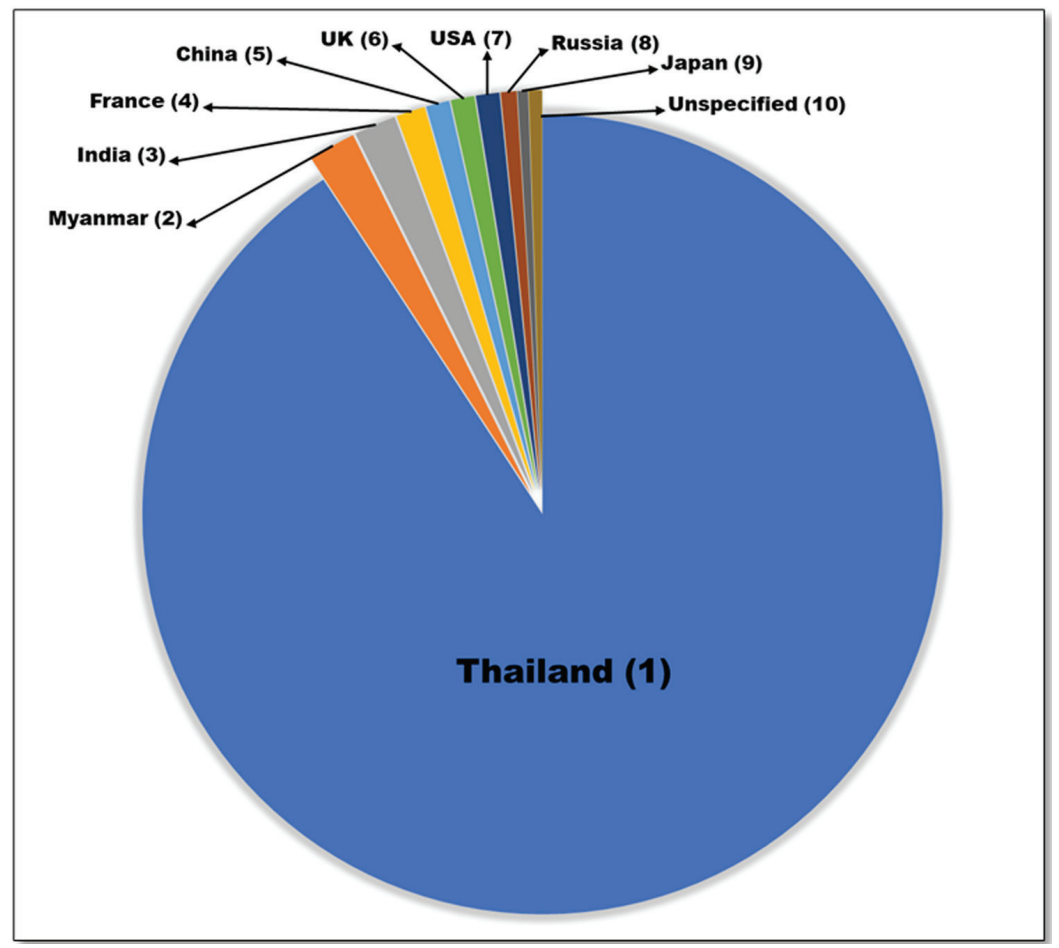

Note 1-10 are the top 10 COVID-19 cases in Thailand ranked by nationality

Figure 1 Top 10 COVID-19 cases in Thailand ranked by nationality

Figure 2 (Left) reveals the number of COVID-19 patients in Thailand by area (province of onset). From the 76 provinces in Thailand, 67 provinces reported confirmed COVID-19 cases. The number of cases varied from 0 , $1-100,>100-200,>200-300,>300-400$, and greater than 400 cases, respectively. The 8 provinces, with the highest reported number of COVID-19 cases, included Bangkok $(n=1879,47.0 \%)$, Chonburi $(n=414,10.4 \%)$, Samut Prakan $(n=235,5.9 \%)$, Phuket $(n=230,5.8 \%)$, Nonthaburi $(n=150$, $3.8 \%)$, Yala $(n=129,3.2 \%)$, Songkhla $(n=127,3.2 \%)$, and Pattani ( $n=96,2.4 \%$ ), respectively. Moreover, the number of cases from these eight provinces accounted for $81.7 \%$ of confirmed cases in Thailand. Other provinces accounted for $<2.0 \%$ each (all information from the Open Government Data of Thailand) (https://data.go.th/dataset/covid-19daily)
Figure 2 (Right) shows the population density in each province of Thailand. Compared to the number of COVID-19 patients in each province of Thailand (Left), the first seven provinces that recorded the highest number of COVID-19 cases (Bangkok, Chonburi, Samut Prakan, Phuket, Nonthaburi, Songkhla, and Pattani) are among the provinces with the highest population density in Thailand (>124.9 people $/ \mathrm{km}^{2}$ ). This excludes Yala province, where the population density is $>74.9-99.9$ people $/ \mathrm{km}^{2}$.

Using the Pearson correlation coefficient to examine the relationships between the population density (people/ $\mathrm{km}^{2}$ ) and the COVID-19 cases in each province, the result showed that the greater the population density, the higher the number of COVID-19 cases $(r=0.829, p$-value $=0.011)$ demonstrating a strong relationship (Table 3). 


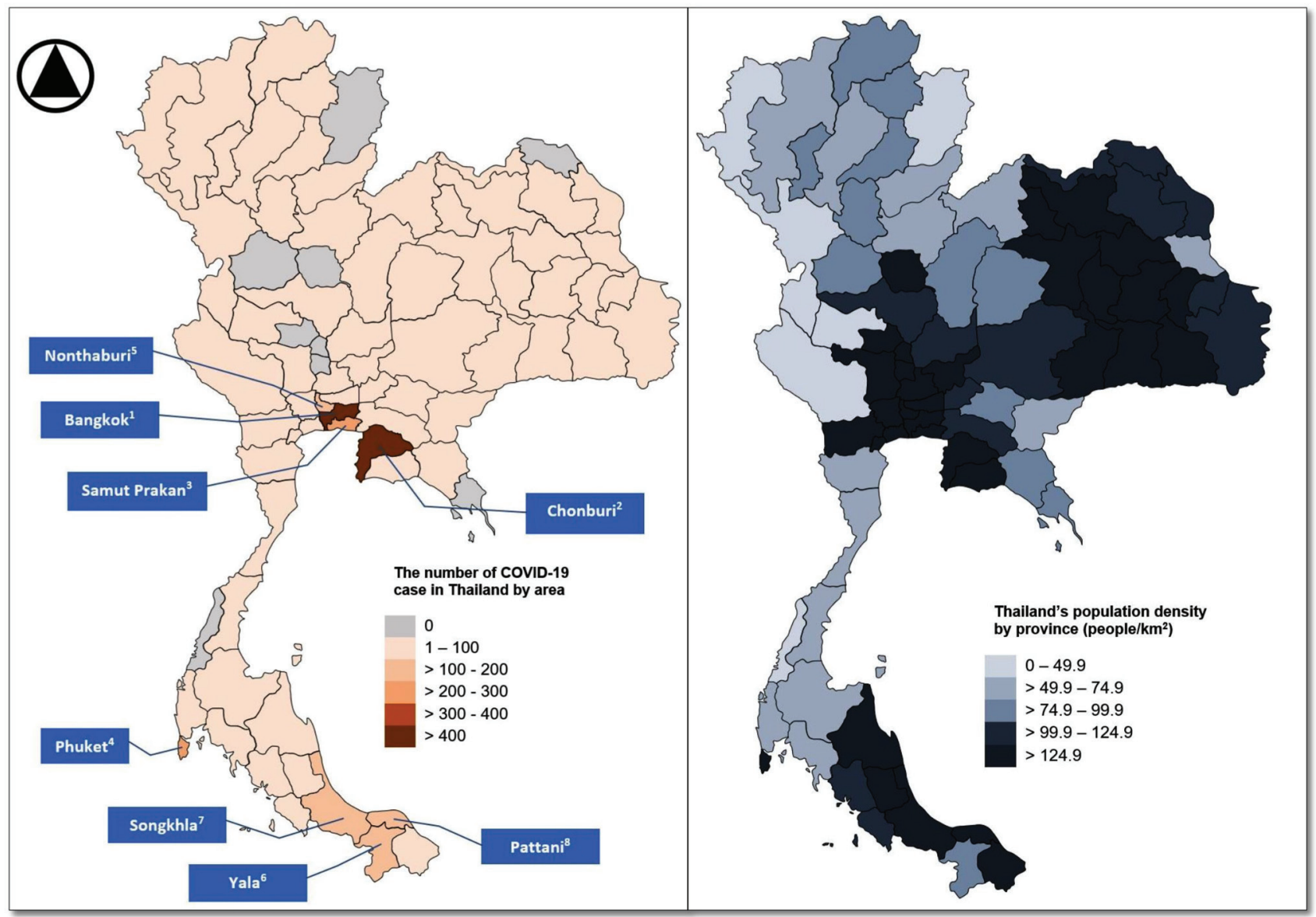

Note (Left) 1-8 is the top 8 COVID-19 cases ranked by the number of COVID-19 patients in each province of Thailand. (Right) The data regarding population density (people/km2) in each province in Thailand was retrieved from The Registration Office Department of the Interior, Ministry of the Interior of Thailand, and The National Statistical Office of Thailand. This figure was modified from "Editable Map of Thailand for PowerPoint," created by PresentationGO (https://www.presentationgo.com/), and the permission to use was provided

Figure 2 (Left) The number of COVID-19 cases in Thailand by area (province of onset). (Right) Thailand's population density by province (people $/ \mathrm{km}^{2}$ )

Table 3 Pearson's correlation coefficients between the number of COVID-19 case and population density

\begin{tabular}{llll}
\hline Variables & & (1) & (2) \\
\hline The number of COVID-19 case & Pearson correlation & 1 & $0.829^{*}$ \\
& Sig. (2-tailed) & & 0.011 \\
Population density & Pearson correlation & $0.829^{*}$ & 1 \\
& Sig. (2-tailed) & 0.011 & \\
\hline
\end{tabular}

Note *Correlation is significant at the 0.05 level (2-tailed)

Sig.=significance 
Table 4 Simple linear regression to predict the number of COVID-19 cases based on population density $\left(\right.$ people $\left./ \mathrm{km}^{2}\right)$

\begin{tabular}{|c|c|c|c|c|c|c|c|c|c|c|}
\hline \multirow{2}{*}{ Model } & \multicolumn{2}{|c|}{$\begin{array}{l}\text { Unstandardized } \\
\text { coeffi cients }\end{array}$} & \multirow{2}{*}{$\begin{array}{l}\text { Standardized } \\
\text { coefficients } \\
\text { Beta }\end{array}$} & \multirow{2}{*}{$t$} & \multirow{2}{*}{ Sig. } & \multicolumn{2}{|c|}{$\begin{array}{l}95 \% \text { confidence } \\
\text { interval for B }\end{array}$} & \multicolumn{3}{|c|}{ Correlations } \\
\hline & B & $\begin{array}{l}\text { Std. } \\
\text { error }\end{array}$ & & & & $\begin{array}{l}\text { Lower } \\
\text { bound }\end{array}$ & $\begin{array}{l}\text { Upper } \\
\text { bound }\end{array}$ & $\begin{array}{l}\text { Zero- } \\
\text { order }\end{array}$ & Partial & Part \\
\hline (Constant) & -46.94 & 179.78 & & -0.26 & 0.803 & -486.85 & 392.96 & & & \\
\hline Population density & 0.41 & 0.11 & 0.83 & 3.63 & 0.011 & 0.13 & 0.69 & 0.83 & 0.83 & 0.83 \\
\hline
\end{tabular}

Note Dependent variable: The number of COVID-19 cases

$\mathrm{B}=$ The unstandardized beta, $\mathrm{t}=\mathrm{t}-$ distribution, Std. error=standard error, Sig.=significance

In addition, simple linear regression was used to predict the number of COVID-19 cases based on population density (people $\left./ \mathrm{km}^{2}\right)$. A significant equation was found $(F$ $(1,6)=13.152, p$-value $<0.050)$, with an $R^{2}$ of 0.687 . The equation was based on the intercept and the unstandardized beta is as follows: The number of COVID-19 cases is equal to $(-46.94+(0.41 \times$ (population density) $)$, where population density is measured in people $\mathrm{km}^{2}$. For interpretation, suppose we need to predict the number of COVID-19 cases when the population density is 200 people $/ \mathrm{km}^{2}$. Based on this equation, the predicted number of COVID-19 cases would be $(-46.94+(0.41 \times 200))=36$ cases $($ Table 4$)$.

\section{Discussion}

Firstly, the results showed that males comprised the majority of COVID-19 patients in Thailand based on gender, especially in those above 31 years old. This study yielded similar findings to the reports Wuhan, China, ${ }^{10}$ the USA $^{11}$, Italy ${ }^{12}$, and Denmark. ${ }^{8}$ This male bias also existed in past pandemics such as the 1918 influenza pandemic ${ }^{13}$, Severe Acute Respiratory Syndrome (SARS) ${ }^{14}$, and Middle Eastern Respiratory Syndrome (MERS). ${ }^{15}$ This phenomenon could be described as the fundamental roles of biological mechanisms and gender differences between males and females. In terms of the biological mechanisms, it is well-established that females have a significant immunological advantage over males. ${ }^{16}$ Females have more enhanced innate and humoral immune responses than males, mounting greater antiviral, inflammatory, and humoral immune responses during infections, thus helping females be less vulnerable to bacterial, fungal, parasitic, and viral infections. ${ }^{16}$ An additional explanation regarding the difference in biological mechanisms is that of studies conducted in an animal samples. As observed in a mouse model of SARS-CoV infection, the endogenous production of estradiol in female mice sheltered their lungs from monocyte-macrophage infiltration and cytokine production to some extent leading to lower virus titers and less severe pulmonary damage. ${ }^{17}$ Additionally, the AngiotensinConverting Enzyme 2 (ACE2) receptor, to which the SARSCoV2 virus S1 spike protein binds in alveolar epithelial cells of the lungs, is 2-fold more in the kidney of male mice, resulting in more significant ACE2 activity in the male kidney. ${ }^{18}$ This reduced ACE2 activity in female mice and is also due to estradiol irrespective of the sex chromosome complement. ${ }^{7}$ Though this has not yet been verified, there is a possibility that ACE2 may play a role in the sex bias in COVID-19 cases. There is an urgent need for exploration of sex-specific regulation of ACE2 in COVID-19 pathogenesis, including that of the lung, heart, and brain, as well as the underlying effects estrogens may have on the reduction of the expression levels of the receptor for the SARS-CoV2 virus. $^{19}$ 
As for possible gender factors associated with the male bias in COVID-19, less likelihood of taking protective actions (e.g., handwashing, wearing masks, staying home, canceling travel, social distancing) ${ }^{20}$, seeking medical help (e.g., testing for SARS-CoV-2, turn to medical professionals early) ${ }^{21}$, engaging in a better lifestyle (e.g., not smoking, not drinking alcohol ${ }^{22}$, and fewer comorbidities (e.g., cardiovascular diseases) ${ }^{23}$ in males might play a role. Therefore, the government should focus publicity towards this male-bias situation and focus on motivating male citizens to take a more active part in fighting against COVID-19. Furthermore, considerations of the possible unwillingness of men to receive the vaccine injection or other treatments should also be given when propagating the use of the treatments. The present study's findings showed that younger adults aged 17-46 years old were the most infected group in Thailand (65.6\%), which is similar to findings in studies from the USA and India., ${ }^{5,24}$ The possible explanation is that, since younger adults are the mainstay of the frontline workforce (e.g., medical staff, retailers, and public transportation drivers ), the protection standard may be more difficult to achieve in these occupations, putting them at a higher risk of contracting the infection and thus are more vulnerable to COVID-19. Moreover, the younger population tends to live a more colorful social life leading to more exposure to others, in addition to the likelihood of them having mild or no symptoms ${ }^{5}$, and the probability of unintentional transmission. It was also reported that those with comorbidities (e.g., hypertension, diabetes, cardiovascular disease), especially older adults, are more susceptible to COVID-19 and have a higher mortality rate. ${ }^{25}$ Whereas, younger adults are less likely to have underlying diseases and thus, might be less cautious of taking adequate preventions against COVID-19. ${ }^{26}$

Thailand has a cumulative number of COVID-19 cases, lower than many countries in Asia. ${ }^{27}$ Although the reported number of COVID-19 cases occurred sporadically, uncontrolled cases were minimal. Overall, of 3,998 COVID-19 cases, $85.6 \%$ were Thai people, and $14.4 \%$ were patients of 64 nationalities-most of them from Asian countries, such as Myanmar, India, China, and Japan (Figure 1). This accounted for almost $33.0 \%$ of non-Thai citizen COVID-19 patients in Thailand. The reason most foreign COVID-19 patients are from these countries may be their close proximity to Thailand, especially Myanmar and China. Therefore, at the beginning of the pandemic, people were still able to travel in and out of Thailand through tourism and non-formal occupations. ${ }^{28}$ Another explanation could be that most tourists in Thailand are from these countries; China (39.8\%), Japan (10.2\%), India (8.3\%), and Myanmar (1.7\%), which account for approximately $60.0 \%$ of travelers in Thailand. ${ }^{29}$

This study indicated that population density is significantly associated with the number of COVID-19 cases and that almost all the provinces with the highest population densities have the most infection numbers. The present study yielded similar findings to a previous study from India. ${ }^{30}$ Thus, population density may be related to the ability to social distance ${ }^{9}$, which is a crucial factor in the transmission of COVID-19 as well as most effective prevention to disease transmission, especially from asymptomatic individuals or those with mild and inconspicuous symptoms. ${ }^{31}$ A nationwide study measuring the effectiveness of social distancing policies in the United States suggested that stay-at-home orders were associated with an increase (35.0\%) in social distancing and subsequent marked reductions in COVID-19 incidence $(29.0 \%)$ and mortality $(35.0 \%){ }^{32}$ revealing the benficial contribution of social distancing in the control of COVID-19. Additionally, contact rates may be enhanced in areas with greater population density, such as large or metropolitan cities, which have a higher possibility of coming into close contact with others.

It is also suggested that the opportunity for effective contacts is mostly driven by crowding in denser areas 
regardless of transportation accessibility and median income, boosting the contact rates necessary for disease spread. ${ }^{33}$ It was reported in several studies that there is a strong correlation between population density and absolute humidity, which encourages the spread of the COVID-19. However, the effect of higher absolute humidity on transmitting the disease remains controversial. A systematic review that included worldwide related studies found that wet climates seem to reduce the spread of COVID-19. ${ }^{34}$ While a study conducted in Brazil, where the climate is similar to Thailand, found that in the coldest countries or periods under cool temperatures, average relative humidity favors COVID-19 transmission. ${ }^{35}$

The study has several limitations. Firstly, given the retrospective nature of the data, inherent biases exist. Secondly, given that this is an observational, archival, retrospective study, there is a remarkable difference in the number of patients included in each group. Thirdly, considering the study used secondary data, there was a lack of control over the data collection process. With secondary data, authors are less able to correct the source's errors during data collection. However, the authors treated the data with caution.

\section{Conclusion}

Our study's findings yielded similarities to previous studies from several countries such as China, the United States, Italy, and Denmark, revealing that Thai males seemed to become infected by COVID-19 more than females. Furthermore, $66.0 \%$ of the COVID-19 patients were individuals whose ages ranged between 17 and 46 . Moreover, this is the first study to present the effect of age, sex, and environmental factors on COVID-19 in Thailand. The result showed that the higher the population density, the higher the number of COVID-19 cases, as the population density is significantly associated with COVID-19 cases. This investigation provides intervention planning implications during potential future pandemics, especially in people at higher risk, such as males aged 17-46 and people living in a high-density area.

\section{Acknowledgement}

We thank the Open Government Data of Thailand, the Registration Office Department of the Interior, Ministry of the Interior of Thailand, and the National Statistical Office, Thailand, for sharing the valuable data. We also thank PresentationGO (https://www.presentationgo.com/) for the permission to modify "Editable Map of Thailand for PowerPoint" for Figure 2.

\section{Funding sources}

This research did not receive any specific grant from funding agencies in the public, commercial, or not-for-profit sectors.

\section{Conflict of interest}

There are no conflicts of interest to declare.

\section{References}

1. Huang C, Wang Y, Li X, Ren L, Zhao J, Hu Y, et al. Clinical features of patients infected with 2019 novel coronavirus in Wuhan, China. lancet 2020;395:497-506.

2. Guan W-j, Ni Z-y, Hu Y, Liang W-h, Ou C-q, He J-x, et al. Clinical characteristics of coronavirus disease 2019 in China. N Engl J Med 2020;382:1708-20.

3. COVID-19 CORONAVIRUS PANDEMIC Worldometer. [homepage on the Internet]. Worldometers; 2020 [cited 2021 Mar 17]. Available from: https://www.worldometers.info/ coronavirus/?

4. Srichannil C. The COVID-19 pandemic and Thailand: A psychologist's viewpoint. Psychol Trauma 2020;12:485.

5. Boehmer TK, DeVies J, Caruso E, van Santen KL, Tang S, Black $\mathrm{CL}$, et al. Changing age distribution of the COVID-19 pandemic-United States, May-August 2020. MMWR Morb Mortal Wkly Rep 2020;69:1404.

6. COVID TC, Team R. Severe outcomes among patients with Coronavirus Disease 2019 (COVID-19)-United States, February 
12-March 16, 2020. MMWR Morb Mortal Wkly Rep 2020;69: 343-6.

7. Klein SL, Dhakal S, Ursin RL, Deshpande S, Sandberg K, Mauvais-Jarvis F. Biological sex impacts COVID-19 outcomes. PLoS pathog 2020;16:e1008570.

8. Kragholm K, Andersen MP, Gerds TA, Butt JH, Østergaard L, Polcwiartek C, et al. Association between male sex and outcomes of Coronavirus Disease 2019 (Covid-19)-a Danish nationwide, register-based study. Clin Infect Dis 2020. doi: 10.1093/cid/ciaa924.

9. Rashed EA, Kodera S, Gomez-Tames J, Hirata A. Influence of absolute humidity, temperature and population density on COVID-19 spread and decay durations: multi-prefecture study in Japan. Int J Environ Res Public Health 2020;17:5354.

10. Zhou F, Yu T, Du R, Fan G, Liu Y, Liu Z, et al. Clinical course and risk factors for mortality of adult inpatients with COVID-19 in Wuhan, China: a retrospective cohort study. Lancet 2020; 395:1054-62.

11. Karthik L, Kumar G, Keswani T, Bhattacharyya A, Chandar SS, Rao KB. Protease inhibitors from marine actinobacteria as a potential source for antimalarial compound. PloS One 2014; 9:e90972.

12. Grasselli G, Zangrillo A, Zanella A, Antonelli M, Cabrini L, Castelli A. Baseline characteristics and outcomes of 1591 patients infected with SARS-CoV-2 admitted to ICUs of the Lombardy Region, Italy. JAMA 2020;323;1574-81.

13. Klein S, Pekosz A, Passaretti C, Anker M, Olukoya P. Sex, gender and influenza. Geneva: WHO; 2010;p1-58.

14. Karlberg J, Chong D, Lai W. Do men have a higher case fatality rate of severe acute respiratory syndrome than women do? Am J Epidemiol 2004;159:229-31.

15. Matsuyama R, Nishiura H, Kutsuna S, Hayakawa K, Ohmagari N. Clinical determinants of the severity of Middle East respiratory syndrome (MERS): a systematic review and metaanalysis. BMC Public Health 2016;16:1-10.

16. Ahmed SB, Dumanski SM. Sex, gender and COVID-19: a call to action. Can J Public Health 2020;111:980-3.

17. Channappanavar R, Fett C, Mack M, Ten Eyck PP, Meyerholz DK, Perlman S. Sex-based differences in susceptibility to severe acute respiratory syndrome coronavirus infection. J Immunol 2017;198:4046-53.

18. Liu J, Ji H, Zheng W, Wu X, Zhu JJ, Arnold AP, et al. Sex differences in renal angiotensin converting enzyme 2
(ACE2) activity are 17 $\beta$-oestradiol-dependent and sex chromosome-independent. Biol Sex Differ 2010;1:6.

19. South AM, Diz DI, Chappell MC. COVID-19, ACE2, and the cardiovascular consequences. Am J Physiol Heart Circ Physiol 2020;318:H1084-90.

20. Hamel L, Salganicoff A. Is there a widening gender gap in coronavirus stress? [homepage on the Internet]. San Francisco, CA: Kaiser Family Foundation; 2020 [cited 2021 Mar 17]. Available from: https://www.kff.org/policywatch/is-there-widening-gender-gap-in 308 coronavirusstress/

21. Thompson AE, Anisimowicz Y, Miedema B, Hogg W, Wodchis WP, Aubrey-Bassler K. The influence of gender and other patient characteristics on health care-seeking behaviour: a QUALICOPC study. BMC Fam Pract 2016;17: 38.

22. Cai H. Sex difference and smoking predisposition in patients with COVID-19. Lancet Respir Med 2020;8:e20.

23. Conti P, Younes A. Coronavirus COV-19/SARS-CoV-2 affects women less than men: clinical response to viral infection. $J$ Biol Regul Homeost Agents 2020;34:339-43.

24. Ahmad S. Potential of age distribution profiles for the prediction of COVID-19 infection origin in a patient group. Inform Med Unlocked 2020;20:100364.

25. Zheng Z, Peng F, Xu B, Zhao J, Liu H, Peng J, et al. Risk factors of critical \& mortal COVID-19 cases: A systematic literature review and meta-analysis. J Infect 2020;81:e16-25.

26. Nagata JM. Supporting Young Adults to Rise to the Challenge of COVID-19. J Adolesc Health 2020;67:297-8.

27. Allam Z. The second 50 days: a detailed chronological timeline and extensive review of literature documenting the COVID-19 pandemic from day 50 to day 100. In: Allam Z, editor. Surveying the Covid-19 pandemic and its implications. Geelong Victoria: Elsevier; 2020;p.9-39.

28. Sarkar A, Liu G, Jin Y, Xie Z, Zheng Z. Public health preparedness and responses to the COVID-19 pandemic in South Asia: A situation and policy analysis. Glob Health J 2020;4:121-32.

29. International Tourist Arrivals to Thailand 2020 Ministry of Tourism \& Sport 2020 [homepage on the Internet]. Bangkok: Ministry of Tourism and Sports; 2020 [cited 2020 Dec 17]. Available from: https://www.mots.go.th/

30. Bhadra A, Mukherjee A, Sarkar K. Impact of population 
density on Covid-19 infected and mortality rate in India. Mode Earth Syst Environ 2020. doi: 10.1007/s40808-020-00984-7.

31. Qian M, Jiang J. COVID-19 and social distancing. Z Gesundh Wiss 2020. doi: 10.1007/s10389-020-01321-z.

32. VoPham T, Weaver MD, Hart JE, Ton M, White E, Newcomb PA. Effect of social distancing on COVID-19 incidence and mortality in the US. Med Rxiv 2020. doi: 10.1101/2020.06.10. 20127589.

33. Sy KTL, White LF, Nichols BE. Population density and basic reproductive number of COVID-19 across United States counties. Med Rxiv 2020. doi: 10.1101/2020.06.12.20130021.
34. Mecenas P, Bastos R, Vallinoto A, Normando D. Effects of temperature and humidity on the spread of COVID-19: A systematic review. Plos One 2020. doi:org/10.1371/journal. pone.0238339.

35. Auler A, Cássaro F, da Silva V, Pires L. Evidence that high temperatures and intermediate relative humidity might favor the spread of COVID-19 in tropical climate: A case study for the most affected Brazilian cities. Sci Total Environ 2020: 729:139090. 